\title{
Calculating the Contribution Rate of Intelligent Transportation System in Improving Urban Traffic Smooth Based on Advanced DID Model
}

\author{
Ming-wei Li, ${ }^{1}$ Jun Yun, ${ }^{1}$ and Na Liu' \\ ${ }^{1}$ Management School, Wuhan University of Technology, Wuhan 430070, China \\ ${ }^{2}$ The Ministry of Transport Research Institute, Beijing 100029, China
}

Correspondence should be addressed to Ming-wei Li; 467827811@qq.com

Received 23 May 2015; Revised 21 August 2015; Accepted 25 August 2015

Academic Editor: Julien Bruchon

Copyright (C) 2015 Ming-wei Li et al. This is an open access article distributed under the Creative Commons Attribution License, which permits unrestricted use, distribution, and reproduction in any medium, provided the original work is properly cited.

\begin{abstract}
Recent years have witnessed the rapid development of intelligent transportation system around the world, which helps to relieve urban traffic congestion problems. For instance, many mega-cities in China have devoted a large amount of money and resources to the development of intelligent transportation system. This poses an intriguing and important issue: how to measure and quantify the contribution of intelligent transportation system to the urban city, which is still a puzzle. This paper proposes a matching differencein-difference model to calculate the contribution rate of intelligent transportation system on traffic smoothness. Within the model, the main effect indicators of traffic smoothness are first identified, and then the evaluation index system is built, and finally the ideas of the matching pool are introduced. The proposed model is illustrated in Guangzhou, China (capital city of Guangdong province). The results show that introduction of ITS contributes $9.25 \%$ to the improvement of traffic smooth in Guangzhou. Also, the research explains the working mechanism of how ITS improves urban traffic smooth. Eventually, some strategy recommendations are put forward to improve urban traffic smooth.
\end{abstract}

\section{Introduction}

In August 2009, Premier Wen Jiabao clearly indicated the importance of establishing the "Experience China" center and seizing the initiative of the new round global network technology development. Since then, a new wave of Internet of Things (IOT) researching is rising in China. Nowadays, China is on the rapid development and construction of the Internet of Things, which has brought unprecedented opportunities for the management and service of the transportation industry. In 2011, the Ministry of Transport focused on promoting the development of transportation through IOT on the basis of the present development industry situation. During the research, aimed at guaranteeing the better development of transport industry, Guangzhou was chosen as the demonstration area and a "city intelligent transportation application demonstration project based on IOT" was organized. Moreover, as a new IOT product technology, Intelligence Transportation System (ITS) was applied in the traffic industry. Compared with the traditional transportation projects, the system mentioned above shows dynamic, novel, complex, extensive characteristics and so forth. In recent years, ITS has been constructed and applied in China while at the same time it has made certain achievements on improving the urban traffic operation and service so as to make the traffic smooth, safe, green, and convenient.

However, urban intelligent traffic is a complex integrated system, whose development and construction are affected by many factors, such as the urban traffic environment, population structure, geographical location, and economic development level. With the rapid development of urban intelligent transportation, the transportation situation has gained certain improvement. However, considerable attention has been currently paid to the evaluation index system and methods regarding the application effects of ITS. Besides, there are relatively rare researches on the application effects in the micro level of ITS. For example, researches about the contribution of ITS in proving urban traffic environment and travel quality, traffic smoothness, and security are relatively blank. Moreover, European Union issued the Guidebook for 
Assessment of Transport Telemetric Applications: Updated Version in September 1998, which systematically expounded the evaluation thought of ITS project in EU. Besides, it had been used to evaluate the ITS project in London, Paris, and other cities. However, the evaluation is just related to the development and construction effects rather than the involvement with the application effects. In 2000, the United States issued "National ITS Architecture" (version 3.0) and comprehensively expounded the evaluation contents and methods of ITS. The evaluation content stipulated includes evaluation design, performance, cost and profitability analysis, risk analysis, and evaluation results. However, the microlevel research of ITS acting on urban traffic is not involved.

Although in the later research Underwood and Gehring [1] evaluated the ITS application effects from social, individual, and enterprise benefits, the research content and result are still in the macro level. Furthermore, Novak and McDnald [2] studied the potential macroeconomic effects of ITS in the United States, in which direct employment, economic multiplier, productivity, technology diffusion, and competitiveness are included. Moreover, Lee [3, 4], Zavergiu [5], Brand [6], and Beimborn et al. [7] established user efficiency analysis models, cost benefit analysis related models, and some other relevant models, so as to research the economic value of ITS projects. However, these researches are more from the perspective of ITS economic value instead of the improvement of traffic environment; besides, their evaluation indicators are different. Then, Xiao [8] who used the analytic hierarchy process and fuzzy mathematics theory to evaluate the effects of ITS in improving urban comprehensive transportation system once argued that the effects of ITS in improving traffic environment cannot be ignored. In addition, Zhao et al. [9] researched from public transport facilities, service, benefit, and social responsibility four aspects in total so as to establish the comprehensive evaluation index system of urban public traffic system. Additionally, Chen and Liao [10] evaluated ITS application effects from six aspects, namely, economic effect, social effect, resource consumption, environmental impact, and development ability. In all these researches, ITS application effects have been analyzed to a certain extent. However, more researches are still focusing on the economic and overall social effects. Besides, there has not yet been in-depth analysis on the specific effects of ITS to urban traffic. Until 2011, Cao et al. [11] defined and quantified the evaluation index system of ITS application effects from five aspects: comfort, safety, convenience, timeliness, and coordination, which has achieved a certain innovation and laid the foundation for the further study. However, it appeared that there have been some deficiencies with the evaluation method. The limitations of the methods led to the complexity of the evaluation process and affected the authenticity of the results. Therefore, in order to ensure the authenticity of the evaluation results, more suitable innovation methods should be developed and employed.

However during this period certain results in terms of the researches of evaluation methods have been obtained. For instance, Leviäkangas and Lähesmaa [12] discussed the application of AHP to analyze the cost benefits of ITS. It is too subjective to determine the weights of the efficiency indicators and this might widen the gap between evaluation results and actual situation. Moreover, Mattingly [13] constructed a model to show the value of ITS project in the monetary form, which was integrated through the analytic hierarchy process and multiple attribute value function method. After that, the model was used to evaluate ITS effects of Anaheim in California, thus confirming the feasibility of the model. However, the model cannot evaluate the application effects of the microlevel object effectively. Wang and Walton [14] discussed the grey correlation analysis (GRA) in evaluating ITS project. Zhang et al. [15] combined analytic hierarchy process with grey correlation method to evaluate the effects of the subsystems of ITS. Nevertheless, all these researches still cannot avoid the influence by the model characteristics; namely, the subjective evaluation results are stronger, which can seriously affect the veracity of the practical evaluation results.

In order to get a better evaluation model, some scholars proposed DID model due to the mature theoretical basis and practical verification of the model. Moreover, DID is more suitable for the evaluation of the benefits of new policy and the results are also more robust. For example, Wooldridge [16] established corresponding DID models according to different data types, while Ai and Norton [17] and Puhani [18] studied the parameter estimation computing method of generalized linear equation in DID model. Moreover, Drykker [19] used Wooldridge's test to verify the correlation between random errors and then corrected the model by generalized least squares method. By studying the minimum wage system in Britain from 1991 to 2000, Galiani et al. [20] evaluated the effects of minimum wage system on employment. Besides, Conti [21] calculated the contribution rate of euro in improving per capita GDP and labor productivity level by DID model. Lewis and Reiley [22] researched the contribution of offline sales products advertising for profit change. In addition, Liang and Zhou [23], Wu [24], Wang [25], and Deng and Wang [26] innovatively selected DID model to analyze the contribution of soil and water conservation engineering, new agriculture insurance policy and foreign strategic investment, and so forth. However, most researches focus on the fields of medical, equity, and economic reform, which could be inflicted with great short-time changes and easiness to control group. However, there are rare researches in the transportation field, while at the same time the applications are lacking innovation. Furthermore, researches on effects of ITS in improving urban traffic congestion are relatively blank. With more difficulties in choosing the control group, there would be more limitation in terms of the application of DID. Besides, the complexity of ITS also determines the difficulties in selecting control group. Thus, it is necessary to improve the DID model, and the innovative introduction of MDID mode is very important.

Despite the achievements acquired by the researches in the traffic smooth field [27-31], more researches are focusing on the cause and influence factors of traffic congestion or other fields. Besides, there are relatively scarce quantitative researches between transportation operation service and ITS. Although some scholars have studied the relationship between traffic smooth and ITS, there are still limited qualitative researches. All of these may lead to the fact that specific functions of ITS in improving traffic smooth cannot 
be expressed clearly. Therefore, strengthening quantitative research of ITS in improving urban traffic congestion is particularly important and necessary [32].

In order to acquire more scientific ITS investment and technology-integrated application with higher efficiency, this paper takes Guangzhou (capital city of Guangdong province, China) as an example (Guangzhou city is the ITS demonstration city in China) based on comprehensive analysis. After that, urban traffic smooth is chosen as the research object. Based on the literature analysis from domestic and foreign research results, characteristics of ITS and its influence factors have been refined. Then, relevant analysis has been conducted on the function of ITS to urban traffic smooth. In addition, a set of evaluation index system has been built so as to comprehensively, objectively, and accurately reflect the benefits of ITS in improving urban traffic smooth. Additionally, the indexes related to urban traffic smooth are extracted firstly, then the indexes which are greatly influenced by ITS are stripped out, and finally the influencing factors of these indexes are figured out. Finally, with advanced DID model (MDID, matching difference-in-difference) and other related econometric models, the contribution rate is calculated. Through the research, the contribution rate of ITS in improving Guangzhou's traffic smooth has been acquired, and the mechanism of ITS in perfecting urban traffic smooth has been proposed.

\section{Model Formulation}

\subsection{Introduction to DID Model}

2.1.1. DID Model. General DID estimation model is

$$
y_{i}=\beta+\alpha_{i} d_{i}+u_{i}
$$

In the formula, $d_{i}=1$ means experimental object, and $d_{i}=0$ means control object. Average treatment effect on the treated ATT measures the average return of experimental group and control group:

$$
\alpha^{\mathrm{ATT}}=E\left(\alpha_{i} \mid d_{i}=1\right)
$$

Investigating dynamic change and introducing time variable to the estimation model:

$$
y_{i t}=\beta+\alpha_{i} d_{i t}+u_{i t} \text {. }
$$

The virtual variable $t=t_{0}$ is time section before policy implemented, and $t=t_{1}$ is the time section after policy implemented. Moreover, policy implementation effect is only acting on the experimental group. Observation time meets $t_{0}<k<t_{1}$, and the formula is acquired as follows:

$$
\begin{aligned}
& E\left[y_{i t} \mid d_{i}, t\right] \\
& \quad= \begin{cases}\beta+E\left[\alpha \mid d_{i}=1\right]+\varepsilon_{t} & \text { if } d_{i}=1, t=t_{1} \\
\beta+\varepsilon_{t} & \text { others. }\end{cases}
\end{aligned}
$$

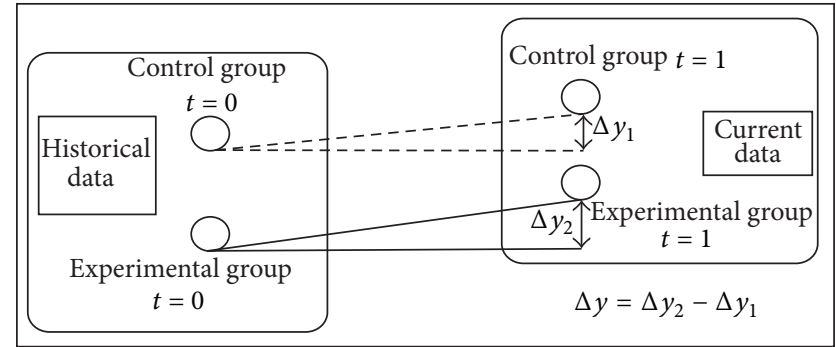

FIGURE 1: Application ideas of DID model.

Here the value of ATT is shown:

$$
\begin{aligned}
& \alpha^{\mathrm{ATT}}=E\left[\alpha \mid d_{i}=1\right] \\
&=\left\{E\left[y_{i t} \mid d_{i}=1, t=t_{1}\right]-E\left[y_{i t} \mid d_{i}=1, t=t_{0}\right]\right\} \\
&-\left\{E\left[y_{i t} \mid d_{i}=0, t=t_{1}\right]-E\left[y_{i t} \mid d_{i}=0, t=t_{0}\right]\right\} .
\end{aligned}
$$

Because $E\left[\widehat{\mathrm{ATT}}_{\mathrm{DID}}\right]=\alpha^{\mathrm{ATT}}$, the estimator of DID is

$$
\widehat{\mathrm{ATT}}_{\mathrm{DID}}=\left[\bar{y}_{t_{1}}^{1}-\bar{y}_{t_{0}}^{1}\right]-\left[\bar{y}_{t_{1}}^{0}-\bar{y}_{t_{0}}^{0}\right]
$$

DID is the unbiased estimators of ATT. The estimator can not only measure the effects before and after the policy implemented but also measure the policy differences between experimental group and control group. After that, the policy implementation effects are obtained.

Here, setting the area that has built the ITS as "experimental group," the area without ITS is developed as "control group." DID model can effectively control the effects of other possible factors. Besides, it can not only distinguish the individual difference in experimental group after using ITS but also separate time differences of different areas. Then it comes to the identification of the application effect of ITS (Figure 1).

From the perspective of the DID model research and application, the selection of control group mainly relies on subjective judgment and lack of objective and quantitative evaluation standard. When control group is a single individual, the results will depend on the individual data to a great extent and result in poor robustness model. Therefore, it is necessary to improve the DID model.

2.2. Introduction to Matching Algorithm. Due to the strong subjectivity of DID model in selecting control group, the authenticity of evaluation results will be affected. Thus, matching algorithm is introduced in the paper to solve the problem. In terms of matching algorithm, adopting an approximation experimental algorithm is implemented to distinguish experimental group and control group effectively. Matching algorithm believes that individuals share the same characteristics, due to which they also have the same response to the same policy variables. That is to say, the decisionmaking behaviors of experimental group and control group are not affected by unobservable variables. Moreover, matching algorithm can enlarge the select range of control group, which can avoid the subjective randomness in selecting control group and eliminate the estimation deviation caused 
by nonmutual support domain and nonidentical distribution [33].

Matching model assumes that the selection biases are entirely determined by observable variables and it also rules out the selection biases caused by unobservable factors. It means that when the control variables are determined, whether affected by policy or not, they will have nothing to do with the value of index $Y$. Call it conditional independence assumption (CIA), and mathematical formula is

$$
E(Y \mid X, d=1)=E(Y \mid X, d=0), \quad Y \perp d \mid X .
$$

The CIA assumption in matching model would limit some variables selected into control group, but the restriction does not cause interference to the precision of results. It is for the reason that DID model allows the existence of observation factors.

Here, setting $\alpha_{0}^{\mathrm{ATT}}$ is the ATT of control variable, and $\alpha_{1}^{\mathrm{ATT}}$ is the ATT of experimental group. When CIA assumption is satisfied, formulas are acquired as

$$
\begin{aligned}
\alpha_{0}^{\mathrm{ATT}} & =E\left[y_{i t} \mid d_{i}=0, t=t_{1}\right]-E\left[y_{i t} \mid d_{i}=0, t=t_{0}\right] \\
& =0 .
\end{aligned}
$$

That is to say, the change of control group is 0 before and after the policy implemented. Therefore, $\alpha^{\mathrm{ATT}}$ is

$$
\begin{aligned}
\alpha^{\mathrm{ATT}} & =\alpha_{1}^{\mathrm{ATT}}-\alpha_{0}^{\mathrm{ATT}}=\alpha_{1}^{\mathrm{ATT}}-0 \\
& =E\left[y_{i t} \mid d_{i}=1, t=t_{1}\right]-E\left[y_{i t} \mid d_{i}=1, t=t_{0}\right]
\end{aligned}
$$

However, there will be multidimensional problems due to the increasing matching strategy with the rise of dimension $X$. In the early method, covariate $(\mathrm{CV})$ is used for the calculation, which would result in "dimension disaster (when the dimension increased, the volume of space will increase quickly, which lead to the fact that the available data will become very sparse)" and the calculation amount is too large. In order to solve the multidimensional problem, Rosenbaum and Rubin [33] put forward the propensity score (PS) as a covariate function. If CV meets CIA hypothesis, then PS could also meet the requirement. Besides, the dimension reduction can be completed successfully by transferring the information contained in $\mathrm{CV}$ to PS. Therefore, $\operatorname{PS}(X)$ is selected to replace the CV's $X$, and formula $Y \perp d \mid X \Rightarrow Y \perp$ $d \mid p s(X)$ is employed to achieve the dimension reduction:

$$
\begin{aligned}
& \operatorname{Pr}(D=1 \mid Y(0), Y(1), \operatorname{PS}(X))=E(D=1 \mid Y(0), \\
& Y(1), \operatorname{PS}(X)) \\
& =E[E(D=1 \mid Y(0), Y(1), \operatorname{PS}(X), X) \mid Y(0), \\
& Y(1), \operatorname{PS}(X)]=E[E(D=1 \mid Y(0), Y(1), X) \mid \\
& Y(0), Y(1), \operatorname{PS}(X)]=E[E(D=1 \mid X) \mid Y(0), \\
& Y(1), \operatorname{PS}(X)]=E[\operatorname{PS}(X) \mid Y(0), Y(1), \operatorname{PS}(X)] \\
& \quad=\operatorname{PS}(X), \\
& \operatorname{Pr}(D=1 \mid Y(0), Y(1), \operatorname{PS}(X)) \\
& \quad=\operatorname{Pr}(D=1 \mid \operatorname{PS}(X))=\operatorname{PS}(X) .
\end{aligned}
$$

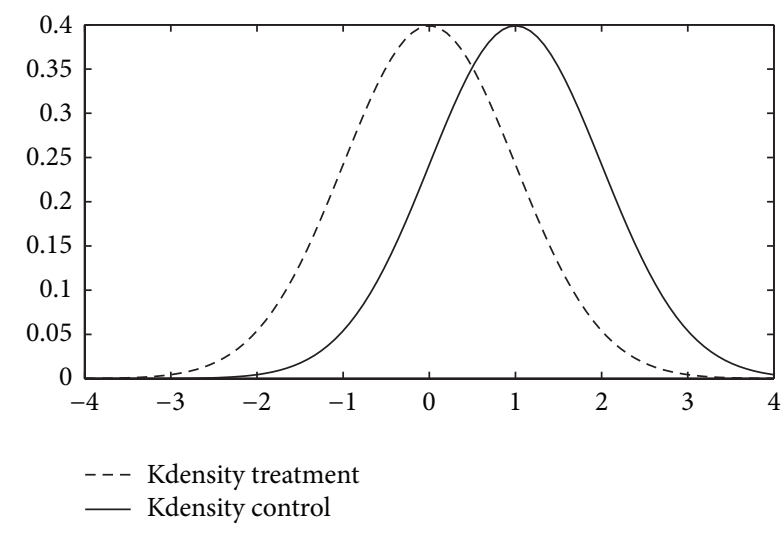

FIGURE 2: Common support domains.

When dealing with PS, Heckman believed that Logist (Logist model uses cumulative Logist distribution function to describe the relationship between selection probability and explanatory variables and limited the value of explained variables ranging from 0 to $1: p_{i}=E\left(Y=1 \mid X_{i}\right)=$ $e^{\beta_{0}+\beta_{1} X_{i}} /\left(1+e^{\beta_{0}+\beta_{1} X_{i}}\right)$; the odds ratio selection or not selection is $p_{i} /\left(1-p_{i}\right)$, taking logarithm of the odds ratio to obtain the measurement model: $\left.L_{i}=\ln \left(p_{i} /\left(1-p_{i}\right)\right)=\beta_{0}+\beta_{1} X_{i}+\varepsilon_{i}\right)$ has more advantages than Probit (Probit model uses the standard normal distribution function to describe the relationship between the selection probabilities and the explanatory variables and limited the value of explained variables ranging from 0 to 1: $p\left(Y_{i}=1\right)=\Phi\left(z_{i}\right)=\int_{-\infty}^{z_{i}}(1 / \sqrt{2 \pi}) \exp \left(-s_{i}^{2} / 2\right) d s$; then it implemented simple inverse function transformation and got the following: $\left.z_{i}=\Phi^{-1}\left(p_{i}\right)=\beta_{0}+\beta_{1} X_{i}+\varepsilon_{i}\right)$. Therefore, the estimation values of matching can be obtained with the following formula:

$$
\widehat{\operatorname{ATT}}_{\text {Matching }}=\frac{1}{N_{1}} \sum_{i=1}^{N_{1}}\left(y_{1 i}-\sum_{j=1}^{N_{0}} w_{i j} y_{0 j}\right) \text {. }
$$

$N_{0}$ and $N_{1}$ refer to the total number of individuals. $w_{i j}$ means the differences between experimental group and control group, and it meets $w_{i j} \in[0,1], \sum_{j=1}^{N_{0}} w_{i j}=1$.

Meanwhile, in order to select optimal control group, common support hypothesis is introduced here as $0<P(d=1$ | $X)<1$. The cross region between experimental group and control group is shown in Figure 2.

2.3. Induction to MDID Model. MDID model aims to find optimal control group on the basis of DID model through bringing in matching module and matching algorithm. Then, virtual processing individuals have been developed before the intervention implemented. Last, the virtual processing individual comes to the implementation of the double difference based on the matching selection of control group.

MDID model has the following advantages when it comes to calculating the contribution rate: (1) MDID could solve the human factors generated by DID model. (2) Matching algorithm could not solve time fixed effects, but DID could. (3) MDID allows the existence of invisible factors. 
TABLE 1: Basic principle of MDID.

\begin{tabular}{lccc}
\hline & Before the policy change & After the policy change & Differential value \\
\hline Experimental group & $\beta_{0}+\beta_{2}+\alpha+\delta$ & $\beta_{0}+\beta_{1}+\beta_{2}+\gamma+\alpha+\delta$ & $\Delta y_{t}=\beta_{1}+\gamma$ \\
Control group & $\beta_{0}+\beta_{2}+\delta$ & $\beta_{0}+\beta_{1}+\beta_{2}+\delta$ & $\Delta y_{c}=\beta_{1}$ \\
Differential value & - & - & $\Delta \Delta y=\gamma$ \\
\hline
\end{tabular}

(4) Matching process does not need lots of data, which makes it possible to build larger optional libraries. (5) MDID model is relatively complete and easy for the inspection and inference.

According to the DID model and matching estimator, MDID estimator is established as follows:

$$
\begin{aligned}
& \widehat{\mathrm{ATT}}_{\text {MDID }} \\
& =\frac{1}{N_{1}} \sum_{i=1}^{N_{1}}\left\{\left(y_{1 i t_{1}}-y_{1 i t_{0}}\right)-\sum_{j=1}^{N_{0}} w_{i j}\left(y_{0 j t_{1}}-y_{0 j t_{0}}\right)\right\} .
\end{aligned}
$$

In view of the above estimators, considering the other influencing factors in control variables, the following panel model is constructed here to estimate ATT:

$$
w_{i j} y_{i t}=\beta_{0}+\beta_{1} t_{i t}+\beta_{2} x_{i t}+\alpha_{i} d_{i t}+\gamma t_{i t} d_{i t}+\delta_{i}+\mu_{i t} .
$$

Among them, $y_{i t}$ is random variable, $w_{i j}$ is weight, and $x_{i t}$ is control variable. $\beta_{0}, \beta_{1}$, and $\beta_{2}$ are coefficient vectors, and $\beta_{1}$ means how the economic behaviors of the experimental group and control group change with time under the policy intervention. $\delta_{i}$ and $u_{i t}$ are random disturbance items, which are not changing with time. $\alpha_{i}$ is the difference between control group and experiment group and it does not change with time. $t_{i t} d_{i t}$ is the cross term of virtual variable; $\gamma$ is the target variable and it is the change degree of the experiment group after accepting the policy.

The original hypothesis of DID is $H_{0}: \gamma=0$; when there is no policy intervention, $\gamma=0$, and DID effects of experimental group and control group are 0 .

Table 1 summarizes the basic principle of MDID method.

\section{Numerical Study}

\subsection{Analysis of Smooth Indicators}

3.1.1. Qualitative Analysis. Traffic smooth can be explained from two aspects: smooth state and smooth efficiency. Smooth state can be understood as road unimpeded, which could be represented by urban average traffic running speed. Urban traffic smooth depends on traffic conditions of each section or road intersection in the whole traffic network. Generally speaking, lots of congestion reasons resulted in poor traffic smooth, with the main reasons being the mismatching and incompatibility of traffic demands and supplies.

Traffic demands are mainly influenced by urban economy, traffic composition, motorized travelling, and other factors. Among them, urbanization process affects travel demands, for the reason that more urban population and advanced economy mean greater travel demands. Besides, traffic forms could directly determine the motorized travel demands and
TABLE 2: Main impact indicators of traffic smooth.

\begin{tabular}{lcc}
\hline Category & Indicator contents & Relevance to the smooth \\
\hline $\begin{array}{l}\text { The social } \\
\text { economic }\end{array}$ & $\begin{array}{c}\text { Population } \\
\text { GDP }\end{array}$ & Negative correlation \\
\hline $\begin{array}{l}\text { Traffic } \\
\text { demand }\end{array}$ & $\begin{array}{c}\text { Motor vehicle ownership } \\
\text { Civilian car ownership }\end{array}$ & Negative correlation \\
\hline Road mileage, road area & Positive correlation \\
Traffic supply & $\begin{array}{c}\text { Public vehicle number } \\
\text { Public transportation } \\
\text { passenger }\end{array}$ & Positive correlation \\
& Positive correlation \\
\hline
\end{tabular}

the smooth state of urban traffic. Basic operation directly determines urban traffic intensity, such as travel consumption and distance.

Traffic supply mainly contains urban traffic management and planning, road infrastructure, related transportation service facilities, and so forth. Urban traffic management and planning determine the spatial layout of urban transportation, such as road network structure and travel direction. Moreover, road infrastructure includes road mileage, road area, road network structure, public transportation, rail transportation, and other facilities, while the transportation service facilities mainly include vehicle parking and vehicle transfer.

Based on the above analysis and modeling necessity, factors whose data are quantifiable and accessible are selected to form the indicators, as shown in Table 2.

(1) Population and GDP. Economic development will bring substantial increase in urban population and will also lead to a great travel demand. Moreover, economic development could lead to the production of more purchasing power of motor vehicles. Therefore, the more development the urban economy has gained, the greater the traffic travel demand will be, which also means higher requirement of transportation supply and carrying capacity.

(2) Number of Motor Vehicles. As the visual expression of road traffic and parking demands, vehicle amount largely determines the requirements of motor vehicle travel. In terms of the slowly growing urban roads and tight urban land, the rapid growth of motor vehicles will provide the road with more carrying capacity, which would quickly reach saturation. Besides, the insufficient parking supply capacity will directly result in severe urban traffic congestion.

(3) Road Mileage and Road Area. Urban road is the carrier of urban traffic, and road mileage as well as road areas can directly determine the carrying capacity of the road network. 
TABLE 3: Related data of traffic smooth in Beijing.

\begin{tabular}{llllllllll}
\hline \multicolumn{2}{l}{ Year } & ASPD & GDP & POP & CVECH & RODM & RODA & PVECH & PPER \\
\hline 2000 & 18.9 & 3161 & 1357 & 104.1 & 2471 & 3502 & 10353 & 34.8 \\
2001 & 19.0 & 3711 & 1383 & 114.5 & 2493 & 3701 & 12945 & 39.2 \\
2002 & 19.8 & 4330 & 1423 & 133.9 & 2504 & 3857 & 15046 & 43.5 \\
2003 & 20.1 & 5024 & 1456 & 163.1 & 3347 & 4315 & 16753 & 37.1 \\
2004 & 20.0 & 6033 & 1493 & 182.4 & 4064 & 7287 & 18451 & 43.9 \\
2005 & 23.4 & 6970 & 1538 & 209.7 & 4073 & 7437 & 18503 & 45.0 \\
2006 & 22.5 & 8118 & 1581 & 239.1 & 4419 & 7286 & 19522 & 39.8 \\
2007 & 20.5 & 9847 & 1633 & 273.4 & 4460 & 7632 & 19395 & 42.3 \\
2008 & 23.1 & 11115 & 1695 & 313.7 & 6186 & 8940 & 21507 & 47.1 \\
2009 & 23.1 & 12153 & 1755 & 368.1 & 6247 & 9179 & 21716 & 51.7 \\
2010 & 22.2 & 14114 & 1961 & 449.7 & 6355 & 9395 & 21548 & 50.5 \\
\hline
\end{tabular}

Data sources: Beijing Transportation Development Annual Report.

Longer road and larger areas mean more driving smooth of urban traffic. However, due to the restriction of urban planning and land, construction funds, and many other factors, the growth rate of urban roads is lower than that of motor vehicle. Taking Beijing as an example, the average annual growth of road mileage is $10.12 \%$ from 2005 to 2010 . Excluding the large-scale construction during the 2008 Olympic Games, the average annual growth rate is only $3 \%$, which is less than $13 \%$ of the average annual growth of motor vehicle.

(4) Number of Public Vehicles. After years of exploration, optimizing the traffic travel structure has become more and more important. Besides, improving the carrying capacity and service level of public transport also becomes an important way to solve the urban traffic congestion problem. The number of public vehicles, which plays a positive role in easing urban traffic congestion, could reflect the supply capacity of urban public transport.

(5) Number of Public Transport Passengers. Public transport passenger can describe supply capacity of public transport from the perspective of transportation production. Generally, people believed that, with greater amount of public transport passenger, urban transport operation would turn better. At present, the main public transport travel modes are public electric vehicle (regular bus), mass transit, and taxi.

3.1.2. Quantitative Analysis. The purpose of the quantitative analysis is to clarify the correlation among indicators and the relationship between indicators and traffic smooth. As showed in foregoing analysis, the paper defines average traffic speed of road network as the characterizing indicator of urban traffic smooth. Considering the regularity between indicators and data availability, the paper collects the data of Beijing from 2000 to 2010 for further analysis, as shown in Table 3.

Here, the following symbols are used to represent the name of each indicator:

ASPD: average traffic speed of road network $(\mathrm{km} / \mathrm{h})$. GDP: GDP (hundred million Yuan).
POP: resident population (ten thousand people).

CVECH: number of civilian vehicles (ten thousand vehicles).

RODM: road mileage $(\mathrm{km})$.

RODA: road area (ten thousand $\mathrm{m}^{2}$ ).

PVECH: number of public vehicles.

PPER: number of public transport passengers.

Utilizing EViews 6.0 to implement correlation test, the specific results are shown in Table 4 .

The results showed that the correlation coefficient of GDP, POP, other factors, and ASPD is all above 0.7. With high correlation, these factors are main factors affecting average traffic speed of road network.

Indicators are screened by referring to the existing evaluation achievements about traffic smooth both at home and abroad and following the metering modeling principles of "from general to simple." In terms of screening the independent variables, the CIA assumption in MDID model could provide some supporting functions: independent variables are influenced by "intervention," but it cannot influence the "intervention." According to MDID assumption, variables which cannot meet CIA assumptions will be eliminated. Finally, Granger test is used as the specific implementation method.

Step 1. Invoke the analysis results of speed's factors and establish timing database.

Step 2. Conduct Granger test between influencing factors and ASPD one by one.

Step 3. Strip out the factors of ASPD Granger reason.

The results show that Granger test result of traffic speed is significant $(P$ value $<0.05)$. Hence, the number of public transport passengers' indicator is not suitable for the independent variable of speed.

3.2. Building the Matching Pool. DID model needs a comparison city, while at the same time Guangzhou city is the only ITS demonstration project city in China. Therefore, the control group cannot be the ITS demonstration project city. However, there are two major drawbacks for the manual selection of the control group cities. First, how much difference the control group cities can tolerate? It may be $10 \%$ or $30 \%$. There is no objective standard. Second, in case of one single selected city, the results will heavily depend on the data of the chosen city. Under the circumstances, the introduction of matching process can solve these two issues effectively and provide theoretical support for selecting optimal control group. Before the execution of the matching algorithms, the first thing is to select the cities that can be allowed to enter into the matching pool.

According to the model theory, it should be assumed that policy is exogenous in terms of selecting control group. That is to say, ITS only affects Guangzhou and has no effect on control group cities; or the influences can be ignored. 
TABLE 4: Correlation between indicators.

\begin{tabular}{|c|c|c|c|c|c|c|c|c|}
\hline \multirow{2}{*}{ Probability } & \multicolumn{8}{|c|}{ Correlation } \\
\hline & ASPD & GDP & POP & $\mathrm{CVECH}$ & RODM & RODA & PVECH & PPER \\
\hline \multirow{2}{*}{ ASPD } & 1.000 & 0.748 & 0.703 & 0.727 & 0.805 & 0.830 & 0.826 & 0.704 \\
\hline & - & 0.008 & 0.016 & 0.011 & 0.003 & 0.002 & 0.002 & 0.016 \\
\hline \multirow{2}{*}{ GDP } & 0.748 & 1.000 & 0.982 & 0.992 & 0.967 & 0.929 & 0.893 & 0.828 \\
\hline & 0.008 & - & 0.000 & 0.000 & 0.000 & 0.000 & 0.000 & 0.002 \\
\hline \multirow{2}{*}{ POP } & 0.703 & 0.982 & 1.000 & 0.995 & 0.934 & 0.888 & 0.851 & 0.822 \\
\hline & 0.016 & 0.000 & - & 0.000 & 0.000 & 0.000 & 0.001 & 0.002 \\
\hline \multirow{2}{*}{$\mathrm{CVECH}$} & 0.727 & 0.992 & 0.995 & 1.000 & 0.955 & 0.905 & 0.867 & 0.832 \\
\hline & 0.011 & 0.000 & 0.000 & - & 0.000 & 0.000 & 0.001 & 0.002 \\
\hline \multirow{2}{*}{ RODM } & 0.805 & 0.967 & 0.934 & 0.955 & 1.000 & 0.956 & 0.916 & 0.827 \\
\hline & 0.003 & 0.000 & 0.000 & 0.000 & - & 0.000 & 0.000 & 0.002 \\
\hline \multirow{2}{*}{ RODA } & 0.830 & 0.929 & 0.888 & 0.905 & 0.956 & 1.000 & 0.937 & 0.824 \\
\hline & 0.002 & 0.000 & 0.000 & 0.000 & 0.000 & - & 0.000 & 0.002 \\
\hline \multirow{2}{*}{ PVECH } & 0.826 & 0.893 & 0.851 & 0.867 & 0.916 & 0.937 & 1.000 & 0.800 \\
\hline & 0.002 & 0.000 & 0.001 & 0.001 & 0.000 & 0.000 & - & 0.003 \\
\hline \multirow{2}{*}{ PPER } & 0.704 & 0.828 & 0.822 & 0.832 & 0.827 & 0.824 & 0.800 & 1.000 \\
\hline & 0.016 & 0.002 & 0.002 & 0.002 & 0.002 & 0.002 & 0.003 & - \\
\hline
\end{tabular}

This hypothesis implied a few requirements: (1) the model allows observation factors; (2) in addition to the policy, the influences of remaining factors are the same; (3) the characteristics of control and experimental group are steady.

According to the above requirements and combined with the situation of China's administrative division, 36 center cities are selected to make up the matching pool. However, considering the outlier features of Tibet's data, the investigation only uses Suzhou as the replacement of Lhasa.

MDID model requires that the cross-section data must be implemented before the policy. Therefore, we can choose the data of the 36 cities in 2010 as alternative library cross-section data, as shown in Table 5.

3.3. Analysis of Matching Process. Based on the above data, Probit model is employed to do the robust regression. The results are shown in Table 6.

The results show that in matching Probit regression process the robust test of PVECH's coefficient is nonsignificant, and there is higher colinearity between PVECH and CVEH. After the removal of PVECH, the values of $R^{2}$ and AIC/SIC are experiencing obvious change.

The colinearity problems of RODM and RODA cannot be ignored, and it is unsuitable for them to be put into the same model. Thus, only RODM is retained. Therefore, the statistical magnitude of the 4 variances' Wald $\chi^{2}$ is 19.89 , the value of $P$ is 0.0005 , the likelihood of log pseudo is -2.2760393 , and pseudo $R^{2}$ is 0.5019 , with the fitting degree being acceptable.

Then, the matching process comes to the implementation of Probit regression and calculating the value of PS. Under common support domain, radius matching algorithm method (radius value is $0.1 \%$ ) is used to select control group cities and calculate the weights of each city. The significant control group cities are Shenzhen, Shanghai, and Suzhou. Then, the Gaussian kernel density function $K\left(\| p_{i}-\right.$ $\left.p_{j} \|_{j \in\{d=0\}}\right)=e^{-\left(p_{i}-p_{j}\right)^{2} / 2 \sigma^{2}}$ is employed (setting Gaussian width parameter as 0.1 ). Last, the weight of control group cities is calculated according to the following formula:

$$
\omega_{i}=\frac{K_{i}\left(\left\|p_{i}-p_{j}\right\|_{j \in\{d=0\}}\right)=e^{-\left(p_{i}-p_{j}\right)^{2} / 2 \sigma^{2}}}{\sum K_{i}\left(\left\|p_{i}-p_{j}\right\|_{j \in\{d=0\}}\right)=e^{-\left(p_{i}-p_{j}\right)^{2} / 2 \sigma^{2}}} .
$$

The results are shown in Table 7.

PS value of the remaining 32 cities is less than 0.001 , so it is not listed.

For guaranteeing the robustness of model, doing logarithm process to data, and recalculating PS value, 0.2265 (Guangzhou), 0.4052 (Shenzhen), 0.1697 (Shanghai), and 0.1371 (Suzhou), the results show that the model is provided with good stability.

Therefore, a virtual city composed of 0.403 Shenzhen, 0.139 Shanghai, and 0.458 Suzhou has been set: city $\mathrm{A}=$ $0.403 *$ Shenzhen $+0.139 *$ Shanghai $+0.458 *$ Suzhou. It is supposed that each indicator of city $\mathrm{A}$ is the same to Guangzhou. Then, city A is set as the control group to calculate the contribution rate.

After that, contribution rate is calculated by collecting relevant data of the experimental group (Guangzhou) and control group (Shenzhen, Shanghai, and Suzhou) from 2008 to 2012, as shown in Table 8 .

Contribution rate can be calculated by the changes of $y$ stemming from the changes of $x$ divided by the total changes of $y$. According to Solow Growth model and making a difference of logarithm, the coefficient of virtual variable is the contribution rate. Meanings of variables and indicators are shown in Table 9. Therefore, GRP is set as the group virtual variable. If $G R P=0$, it means that the variable should be in control group. And if GRP = 1, it means that the variable should be in the experimental group. Set ITS as policy virtual 
TABLE 5: Cities and corresponding data in matching pool.

\begin{tabular}{|c|c|c|c|c|c|c|}
\hline City & GDP & CVECH & POP & RODM & RODA & PVECH \\
\hline Shijiazhuang & 34010186.00 & 901653.00 & 1002.81 & 1475 & 4147 & 90657.00 \\
\hline Taiyuan & 17780539.00 & 605048.00 & 354.02 & 1780 & 2432 & 39353.00 \\
\hline Hohhot & 18657116.00 & 321551.00 & 278.76 & 720 & 1609 & 10189.00 \\
\hline Shenyang & 50175400.00 & 984312.00 & 804.65 & 2895 & 5706 & 10275.00 \\
\hline Dalian & 51581600.00 & 944885.00 & 663.82 & 2899 & 4135 & 7145.00 \\
\hline Changchun & 33290329.00 & 664845.00 & 757.70 & 3659 & 6260 & 23935.00 \\
\hline Harbin & 36648538.00 & 652435.00 & 991.81 & 1427 & 3296 & 21618.00 \\
\hline Nanjing & 51306491.82 & 830524.00 & 786.03 & 5599 & 9576 & 19539.00 \\
\hline Hangzhou & 59491687.00 & 1248056.00 & 851.97 & 2194 & 4754 & 70304.00 \\
\hline Ningbo & 51630017.00 & 877434.00 & 744.29 & 1439 & 2379 & 16689.00 \\
\hline Hefei & 29616700.00 & 386060.00 & 540.49 & 2013 & 4323 & 16707.00 \\
\hline Fuzhou & 31234092.00 & 433734.00 & 699.27 & 1101 & 2327 & 11108.00 \\
\hline Xiamen & 20600737.00 & 385391.00 & 353.13 & 1213 & 2994 & 7987.00 \\
\hline Nanchang & 22001059.00 & 362429.00 & 502.66 & 965 & 1806 & 6303.00 \\
\hline Jinan & 39105271.00 & 797359.00 & 674.62 & 4498 & 5907 & 12297.00 \\
\hline Qingdao & 56661900.00 & 975571.00 & 860.77 & 3409 & 5893 & 15544.00 \\
\hline Zhengzhou & 40408926.00 & 963010.00 & 809.04 & 1338 & 3158 & 21572.00 \\
\hline Wuhan & 55659300.00 & 1046500.00 & 944.00 & 2682 & 7273 & 9838.00 \\
\hline Changsha & 45470573.00 & 1008677.00 & 684.35 & 1781 & 3618 & 28502.00 \\
\hline Guangzhou & 107482827.92 & 1598934.00 & 1228.96 & 6986 & 9731 & 7396.00 \\
\hline Shenzhen & 95815101.00 & 1669674.00 & 1016.10 & 12613 & 8941 & 3099.00 \\
\hline Nanning & 18002613.00 & 432199.00 & 702.62 & 1307 & 3205 & 21681.00 \\
\hline Haikou & 6171948.00 & 238038.00 & 159.35 & 111 & 316 & 18808.00 \\
\hline Chengdu & 55513336.00 & 2599300.00 & 1144.37 & 2610 & 6460 & 5819.00 \\
\hline Guiyang & 11218174.00 & 604425.00 & 430.52 & 872 & 1348 & 11416.00 \\
\hline Kunming & 21203700.00 & 1324215.00 & 632.00 & 1420 & 2815 & 2067.00 \\
\hline Xi'an & 32416900.00 & 957162.00 & 845.45 & 2428 & 5342 & 18986.00 \\
\hline Lanzhou & 11003898.00 & 246100.00 & 323.56 & 906 & 2162 & 9146.00 \\
\hline Xining & 6282800.00 & 309900.00 & 221.01 & 433 & 737 & 7448.00 \\
\hline Yinchuan & 7694227.00 & 225597.00 & 185.31 & 506 & 1652 & 6202.00 \\
\hline Beijing & 141135800.00 & 4497200.00 & 1910.96 & 6355 & 9395 & 11584.00 \\
\hline Urumqi & 13385172.00 & 1271400.00 & 311.00 & 1632 & 2005 & 15085.00 \\
\hline Chongqing & 79255800.00 & 1143000.00 & 2872.00 & 5130 & 9931 & 14303.00 \\
\hline Tianjin & 92244600.00 & 1582400.00 & 1263.73 & 5439 & 9159 & 7297.00 \\
\hline Shanghai & 171659800.00 & 1755100.00 & 2256.48 & 4713 & 9299 & 27114.00 \\
\hline Suzhou & 92289100.00 & 1261001.00 & 991.90 & 2904 & 5928 & 7937.00 \\
\hline
\end{tabular}

Data source: urban passenger statistical reports of the Ministry of Transport.

variables and GRP * ITS as cross terms, and the final model is shown as

$$
\begin{aligned}
w * \operatorname{ASPD}= & \beta_{0}+\beta_{1} * \mathrm{RODM}+\beta_{2} * \mathrm{CVECH}+\beta_{3} \\
& * \mathrm{GDP}+\alpha_{1} * \mathrm{GRP}+\alpha_{2} * \mathrm{ITS}+\gamma \\
& * \mathrm{GRP} * \mathrm{ITS}+\mu
\end{aligned}
$$

3.4. Analyzing the Calculated Results. The data above are not in the symmetrical distribution, so it is difficult for the conditional expectation of least squares model to accurately reflect the real situation. Therefore, the paper establishes the following fixed effects estimation model and used quantile regression to achieve fitting.
The estimation and test results of coefficient and variance are shown in Table 10.

The paper can obtain the following conclusions based on the estimation results.

(1) The coefficient of GRP * ITS could reflect the net contribution rate of ITS project to Guangzhou's ASPD, and the value is about 0.0925 . Hence, the net contribution rate of ITS project to the ASPD increasing of Guangzhou is 9.25\%. Moreover, 9.25\% of the effects are contributed by ITS project in terms of improving the traffic smooth.

(2) Variance $R^{2}=0.7041$, which means that $70.41 \%$ of the total variation can be explained by the model 
TABLE 6: Regression results.

\begin{tabular}{|c|c|c|c|c|c|c|}
\hline Variable & Coef. & Robust std. err. & $z$ & $P>z$ & \multicolumn{2}{|c|}{ [95\% conf. interval] } \\
\hline GDP & $1.37 E-07$ & $5.07 E-08$ & 2.7 & 0.007 & $3.74 E-08$ & $2.36 E-07$ \\
\hline $\mathrm{CVECH}$ & $7.01 E-08$ & $2.97 E-07$ & 0.24 & 0.814 & $-5.13 E-07$ & $6.53 E-07$ \\
\hline RODM & -0.0000411 & 0.0001591 & -0.26 & 0.796 & -0.0003529 & 0.0002707 \\
\hline POP & -0.0091995 & 0.0039181 & -2.35 & 0.019 & -0.0168789 & -0.0015201 \\
\hline _cons & -3.895322 & 0.6351935 & -6.13 & 0 & -5.140279 & -2.650366 \\
\hline
\end{tabular}

TABLE 7: PS values and the weights.

\begin{tabular}{lcc}
\hline Significant city & PS & Weight \\
\hline Guangzhou & 0.2465 & 1 \\
Shenzhen & 0.2917 & $40.28 \%$ \\
Shanghai & 0.1034 & $13.89 \%$ \\
Suzhou & 0.3310 & $45.83 \%$ \\
\hline
\end{tabular}

with four variables and two free dummy variables, while the other $30 \%$ is caused by factors that are not included in the model.

(3) Table 10 shows that the intercept coefficient _cons = 0.054003 . Due to the fact that the control group cannot completely lose connection with ITS project, the value indicating the effect proportion of ITS project to control group is $5.4 \%$, and this value can be ignored. Therefore, _cons $=0.054003$ also fully illustrates the scientificity in selecting control group and supporting the authenticity of the contribution results.

(4) The coefficient of policy virtual variables is -0.031374 , which means that traffic smooth of control group is also affected by time factor and other related factors. Besides, traffic smooth level decreased by $3.14 \%$ from the year 2008 to 2012, which shows that traffic smooth of control group is relatively stable during the period, and it is beneficial to use MDID contribution assessment model.

(5) The regression coefficient of group virtual variable is -0.035766 . It means that before the implementation of ITS project, the difference of traffic smooth between control group and experimental group is only $3.58 \%$. It also shows that the selection of control group and experimental group in this paper is quite reasonable.

(6) The coefficients of RODM, CVECH, and GDP are $1.085374,-1.867530$, and 1.865249 , respectively, proving that the RODM and GDP have a positive correlation with traffic smooth, and the correlation value of GDP is higher than RODM. In contrast, CVECH has a negative correlation with traffic smooth.

The applications of ITS will inevitably exert a positive influence on the urban transportation development. However, with the rapid development of the city and coupled with the effects of many other factors on ITS, the urban traffic smooth has not been significantly improved. Therefore, based on these conclusions, the paper puts forward policy recommendations to improve urban traffic smooth from several aspects.

(1) The paper enhances the management level of urban traffic and improve the existing road network structure. City should figure out the requirements of its market economy, take into consideration the current situation of its own traffic, and promote reform of its management system. For example, the city could actively promote the separation of enterprise and government, so as to preferentially develop public transport, strengthen the using of information technology, and develop multicore urban spatial structure. Moreover, in terms of doing road network planning by the government, they should predict the traffic environment in a long period in the future. The situation where the occurrence of the later construction would deny the preoutcomes will be avoided. Last, perfect the static traffic facilities, such as establishing threedimensional garage.

(2) It improves traffic smooth under the condition of ensuring effective urban development process. The development of economy and increasing population is bound to increase the number of motor vehicles. Thus, the traffic smooth state will be affected. Then, traffic demand will be guided reasonably and the traffic congestion will be eased by adopting the price mechanism, such as improving vehicle taxes and parking fees, charging road congestion fees, and implementing public transport travel concessions.

(3) It optimizes urban transportation infrastructure operational state. At present, China's motor vehicle ownership has increased by $15 \%$, while the urban road has just grown by $3 \%$. This ratio is extremely unreasonable. Due to the limitation of urban land resources, it is necessary to maximize the limited land resources and road utilization rate. For example, common cross overpass will be established and intelligent traffic lights will be used to control the intersection. Firstly, set intersection spacing of different road reasonable levels and then strengthen interconnection rates between roads. After that, shorten the travel distance; furthermore, install intelligent traffic display and allocate the traffic flow to be more reasonable. Finally, it comes to reducing travel time.

(4) It reasonably configures traffic composition mode. Firstly, improve facilities and services of public 
TABLE 8: Data of experimental group and control group.

\begin{tabular}{|c|c|c|c|c|c|c|}
\hline City & Year & ASPD & RODM & POP & $\mathrm{CVECH}$ & GDP \\
\hline \multirow{5}{*}{ Shenzhen } & 2008 & 29.90 & 5849 & 933.3250 & 1252747 & $77,867,920.00$ \\
\hline & 2009 & 27.40 & 6035 & 974.6450 & 1419005 & $82,013,176.00$ \\
\hline & 2010 & 26.40 & 6184 & 1016.1050 & 1669674 & $95,815,101.00$ \\
\hline & 2011 & 28.00 & 5977 & 1041.9718 & 1939653 & $115,055,298.00$ \\
\hline & 2012 & 26.50 & 6015 & 1050.7432 & 2210821 & $129,501,000.00$ \\
\hline \multirow{5}{*}{ Suzhou } & 2008 & 31.30 & 5013 & 897.3807 & 840431 & $70,780,900.00$ \\
\hline & 2009 & 25.70 & 5178 & 924.7993 & 1027058 & $77,402,000.00$ \\
\hline & 2010 & 25.80 & 5348 & 991.8973 & 1261001 & $92,289,100.00$ \\
\hline & 2011 & 25.90 & 5524 & 1049.3582 & 1518866 & $107,169,900.00$ \\
\hline & 2012 & 26.00 & 5672 & 1053.3855 & 1778977 & $120,116,500.00$ \\
\hline \multirow{5}{*}{ Shanghai } & 2008 & 16.98 & 15844 & 2102.1141 & 1321229 & $140,698,700.00$ \\
\hline & 2009 & 17.70 & 16071 & 2175.4742 & 1471052 & $150,464,500.00$ \\
\hline & 2010 & 16.64 & 16687 & 2256.4845 & 1755100 & $171,659,800.00$ \\
\hline & 2011 & 15.64 & 16792 & 2325.0594 & 1947515 & $191,956,900.00$ \\
\hline & 2012 & 14.70 & 17316 & 2363.9464 & 2126637 & $201,817,200.00$ \\
\hline \multirow{5}{*}{ Guangzhou } & 2008 & 21.00 & 5434 & 1084.1750 & 1171731 & $82,873,816.00$ \\
\hline & 2009 & 18.70 & 5519 & 1151.1550 & 1340540 & $91,382,135.00$ \\
\hline & 2010 & 22.70 & 6986 & 1228.9649 & 1598934 & $107,482,827.92$ \\
\hline & 2011 & 22.90 & 7072 & 1273.0500 & 1857740 & $124,234,390.00$ \\
\hline & 2012 & 25.30 & 7100 & 1279.5143 & 2041592 & $135,512,000.00$ \\
\hline
\end{tabular}

Data source: statistical yearbook of the cities and traffic statistics yearbook.

TABLE 9: Meanings of variables and indicators.

\begin{tabular}{|c|c|}
\hline Main variable & Variable declaration \\
\hline Decision variable & ASPD \\
\hline Explanatory variable & $\mathrm{CVECH}$ \\
\hline Control variable & RODM, GDP \\
\hline Policy variable & $\begin{array}{c}t_{i t}=1 \text { means after the implementation of } \\
\text { ITS project }(2011-2012) \\
t_{i t}=0 \text { means before the implementation of } \\
\text { ITS project }(2008 \sim 2010)\end{array}$ \\
\hline Category variable & $\begin{array}{l}d_{i t}=1 \text { means the objects of experimental } \\
\text { group } \\
d_{i t}=0 \text { means the objects of control group }\end{array}$ \\
\hline
\end{tabular}

transport, which then can attract more people to take public transportation. For example, the layout of public transport, developing various forms of rapid transit buses, implementing different discount bus cards at peak period, and improving public transport share ratio may be optimizing.

\section{Conclusions and Further Study}

This paper reveals the influence factors and evaluation indexes of ITS on urban traffic smooth, based on the analysis of ITS in terms of improvement of urban traffic smooth. Combining the improved DID model, we calculate the contribution rate of ITS in improving urban traffic smooth. Through innovative study of the DID model, the research overcomes the application limitations of the DID model, which can serve as a useful tool for policy making of transportation department and evaluation of demonstration project. Also, the study provides new insights for quantitative research of urban transportation industry in terms of investment and decision. The result reveals that ITS works to improve urban traffic smooth to some extent. Specifically, ITS helps to relieve the traffic congestion through taking full advantage of the urban road area, reduce vehicle travel time and distance, and improve the urban traffic smooth. In a nutshell, the proposed quantitative analysis methodology in this paper can provide some new insights for ITS decision makers for strategic planning purposes. Moreover, this study can provide theoretical reference for the performance analysis of city's large demonstration projects and innovative ideas for the technical processing of DID model.

Although ITS has improved the traffic smooth to some extent, the improvement of average travel speed is still not obvious as a result of the increase of motor vehicles. In view of the above, the contributions of ITS cannot be ignored in terms of improving the average travel speed. Accordingly, it is necessary to accelerate the construction of ITS and make a practical action in improving urban traffic smooth. Although the modeling methodology proposed in this study provides a new avenue for evaluating the effects of ITS on urban traffic smooth, further extensions are necessary.

(1) The paper identifies the main indicators that affect traffic smooth. However, it is difficult to quantify the related degree between the indicators and ITS, since there are plenty of factors that influence traffic smooth. As such, some high correlation indicators 
TABLE 10: Estimation results of the model.

\begin{tabular}{|c|c|c|c|c|c|c|}
\hline Variable & Coef. & $\begin{array}{l}\text { Bootstrap } \\
\text { std. err. }\end{array}$ & $t$ & $P>|t|$ & \multicolumn{2}{|c|}{ [95\% conf. interval] } \\
\hline RODM & 1.085374 & 0.201156 & $5.400000^{* *}$ & 0.000 & 0.6303271 & 1.54042 \\
\hline $\mathrm{CVECH}$ & -1.867530 & 0.890793 & $-2.100000^{*}$ & 0.065 & -3.882644 & 0.1475842 \\
\hline GDP & 1.865249 & 0.568868 & $3.280000^{*}$ & 0.010 & 0.5783794 & 3.152118 \\
\hline GRP & -0.035766 & 0.050119 & -0.710000 & 0.494 & -0.1491443 & 0.0776114 \\
\hline ITS & -0.031374 & 0.049013 & -0.640000 & 0.538 & -0.1422493 & 0.0795012 \\
\hline $\mathrm{GRP} * \mathrm{ITS}$ & 0.092490 & 0.063868 & 1.450000 & 0.182 & -0.0519902 & 0.2369696 \\
\hline _cons & 0.054003 & 0.094830 & 0.570000 & 0.583 & -0.1605178 & 0.2685238 \\
\hline
\end{tabular}

$t$ statistics in parentheses: ${ }^{*} P<0.05$ and ${ }^{* *} P<0.01$.

may be ignored, and this may further cause a significant bias in the evaluation capability of the model. Accordingly, it is worthy of more attention in a further study.

(2) Because of the special characteristics of ITS such as complexity, dynamism, and the hysteresis of application effects, one key problem is to determine the starting time-point of evaluation firstly. An appropriate starting time-point can guarantee that the evaluation results reflect the application benefits of ITS accurately. Therefore, in the future research, it is necessary to study the evaluation time-point of ITS application effects. Also, it is necessary to choose the point data to evaluate the contribution rate and to strengthen the scientific rationality of the results.

(3) Although the MDID model works well in the selection of control group, it has high requirements of the individuals that enter the matching pool. Therefore, it needs to strengthen the discussion about the selection of control group in further research. As such, DID model can be preferably used in traffic fields.

\section{Conflict of Interests}

All the authors have declared that they have no conflict of interests to this work.

\section{References}

[1] S. E. Underwood and S. G. Gehring, "Framework for evaluating intelligent vehicle-highway systems," Transportation Research Record, vol. 1453, pp. 16-22, 1994.

[2] D. C. Novak and M. McDnald, "A general overview of the potential macroeconomic impacts of ITS investment in the United States," in Proceedings of the Annual Meeting of the Transportation Research Board, Washington, DC, USA, January 1998.

[3] D. B. Lee, Benefit-Cost Evaluation of ITS Projects: Seattle WSDOT Web Site (SE-26), FHWA/FTA Joint Program Office, USDOT, 1999.

[4] D. B. Lee and L. R. Klein, Benefit-Cost Evaluation of ITS Traveler Information: Kiosks, Volpe Center, USDOT, 1997.
[5] R. Zavergiu, "Intelligent transportation systems-an approach to benefit studies," Tech. Rep. TP 12695E, Transportation Development Centre, Montréal, Canada, 1996.

[6] D. Brand, "Applying benefit/cost analysis to identify and measure the benefits of intelligent transportation systems," Transportation Research Record, no. 1651, pp. 23-29, 1998.

[7] E. A. Beimborn, Z. Ren-peng, and M. Neluheni, "A framework and methods for evaluation of benefits of intelligent transportation systems," Transportation Research Board Record 1777, 2001.

[8] H.-B. Xiao, "Evaluation index system and evaluation methods on city integrated transport system," Transportation Science \& Technology, vol. 234, no. 3, pp. 87-90, 2009.

[9] Q. Zhao, S.-M. Huang, S.-X. Di, and G.-S. Lu, "Comprehensive evaluation index system of urban public traffic system," Transport Standardization, vol. 208, no. 11, pp. 83-86, 2009.

[10] B.-W. Chen and X.-F. Liao, "Research on evaluation index system of highway transportation sustainable development," China Journal of Highway and Transport, vol. 22, no. 5, pp. 112116, 2009.

[11] L. Cao, W.-X. Zha, W.-T. Zhao, and S.-B. Wang, "Establishing transfer evaluation index system of BRT," Transport Engineering and Safety, vol. 246, no. 11, pp. 126-128, 2011.

[12] P. Leviäkangas and J. Lähesmaa, "Profitability evaluation of intelligent transport system investments," Journal of Transportation Engineering, vol. 128, no. 3, pp. 276-286, 2002.

[13] S. P. Mattingly, Decision Theory for Performance Evaluation of New Technologies Incorporating Institutional Issues: APP Lineation to Traffic Control Implementation, University of California, Berkeley, Calif, USA, 2000.

[14] Z. Wang and C. M. Walton, "A multicriteria approach for evaluation and alternative selection of ITS deployments," in Proceedings of the 11th Annual World Congress on Intelligent Transportation Systems (ITS '04), Nagoya, Japan, 2004.

[15] Q. Zhang, J.-L. Shen, and C. Li, "Bidding appraisal mechanism and synthetic appraisal method in ITS projects," Journal of Transportation Systems Engineering and Information Technology, vol. 5, no. 4, pp. 18-29, 2005.

[16] J. M. Wooldridge, Introductory Econometrics: A Modern Approach, South-Western College Publishing, 2nd edition, 2002.

[17] C. Ai and E. C. Norton, "Interaction terms in logit and probit models," Economics Letters, vol. 80, no. 1, pp. 123-129, 2003.

[18] P. A. Puhani, "The treatment effect, cross difference and interaction term in nonlinear 'difference-in-differences' models," IZA Discussion Paper 2, 2008. 
[19] D. M. Drykker, "Testing for serial correlation in linear paneldata models," The Stata Journal, vol. 3, no. 2, pp. 168-177, 2003.

[20] S. Galiani, P. Gertler, and E. Schargrodsky, "Water for life: the impact of the privatization of water services on child mortality," Journal of Political Economy, vol. 113, no. 1, pp. 83-120, 2005.

[21] M. Conti, "The introduction of the euro and economic growth: some panel data evidence," Journal of Applied Economics, vol. 17, no. 2, pp. 199-211, 2014.

[22] R. A. Lewis and D. H. Reiley, "Online ads and offline sales: measuring the effect of retail advertising via a controlled experiment on Yahoo!" Quantitative Marketing and Economics, vol. 12, no. 3, pp. 235-266, 2014.

[23] J. Liang and Y. Zhou, "An empirical study on GEM and enterprises innovation," Science Research Management, vol. 34, no. 2, pp. 89-92, 2013.

[24] Y.-L. Wu, "Soil and water conservation projects and national food safety-evidence from the panel data of northeast black soil areas," China Population, Resources and Environment, vol. 24, no. 5, pp. 304-308, 2014.

[25] H. Wang, "New farming maintain to evaluate the contribution of the rural residents' consumption growth in China-based on DID model," Modern Business, no. 2, 2014.

[26] M. Deng and Q.-H. Wang, "Relationship between China's strategic introduction of overseas investment and X-efficiency of Chinese-funded banks," International Business, no. 2, pp. 2130, 2014.

[27] A. Tzedakis, "Different vehicle speeds and congestion costs," Journal of Transport Economics and Policy, vol. 14, no. 1, pp. 81103, 2005.

[28] C. Wright and P. Roberg, "The conceptual structure of traffic jams," Transport Policy, vol. 5, no. 1, pp. 23-35, 1998.

[29] H. Rehborn and M. Koller, "A study of the influence of severe environmental conditions on common traffic congestion features," Journal of Advanced Transportation, vol. 48, no. 8, pp. 1107-1120, 2014.

[30] A. Waadt, "Traffic congestion estimation service mobile assisted positioning schemes in GSM networks," Procedia Earthand Plaetary Science, vol. 1, no. 1, pp. 1385-1392, 2009.

[31] Y.-L. Li and C. Wang, "Urban planning and population density: factors affecting urban traffic development research," Xinjiang Social Science, no. 3, pp. 42-46, 2013 (Chinese).

[32] M. Anisimova, "Darwin and Fisher meet at biotech: on the potential of computational molecular evolution in industry," BMC Evolutionary Biology, vol. 15, article 76, 2015.

[33] P. R. Rosenbaum and D. B. Rubin, "The central role of the propensity score in observational studies for causal effects," Biometrika, vol. 70, no. 1, pp. 41-55, 1983. 


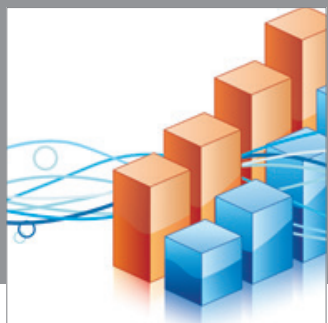

Advances in

Operations Research

mansans

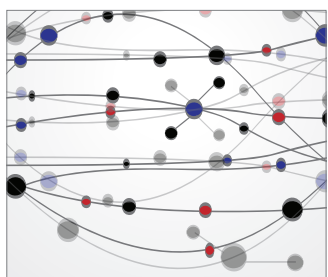

The Scientific World Journal
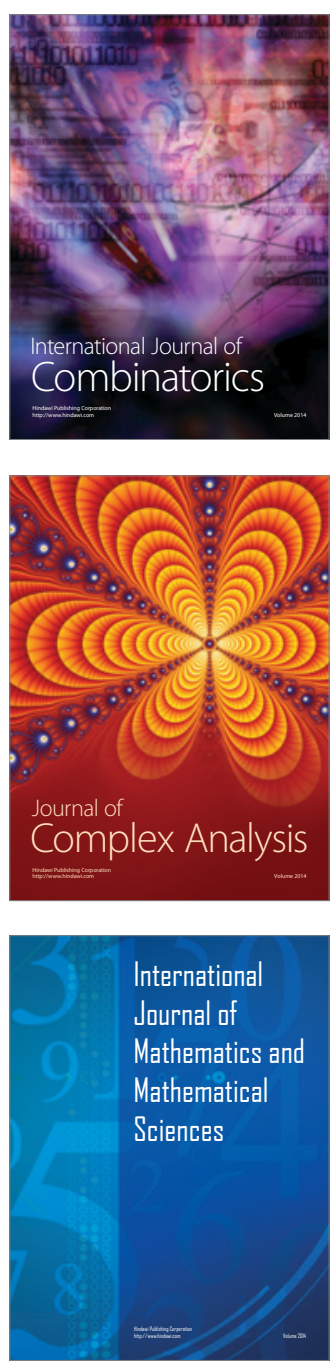
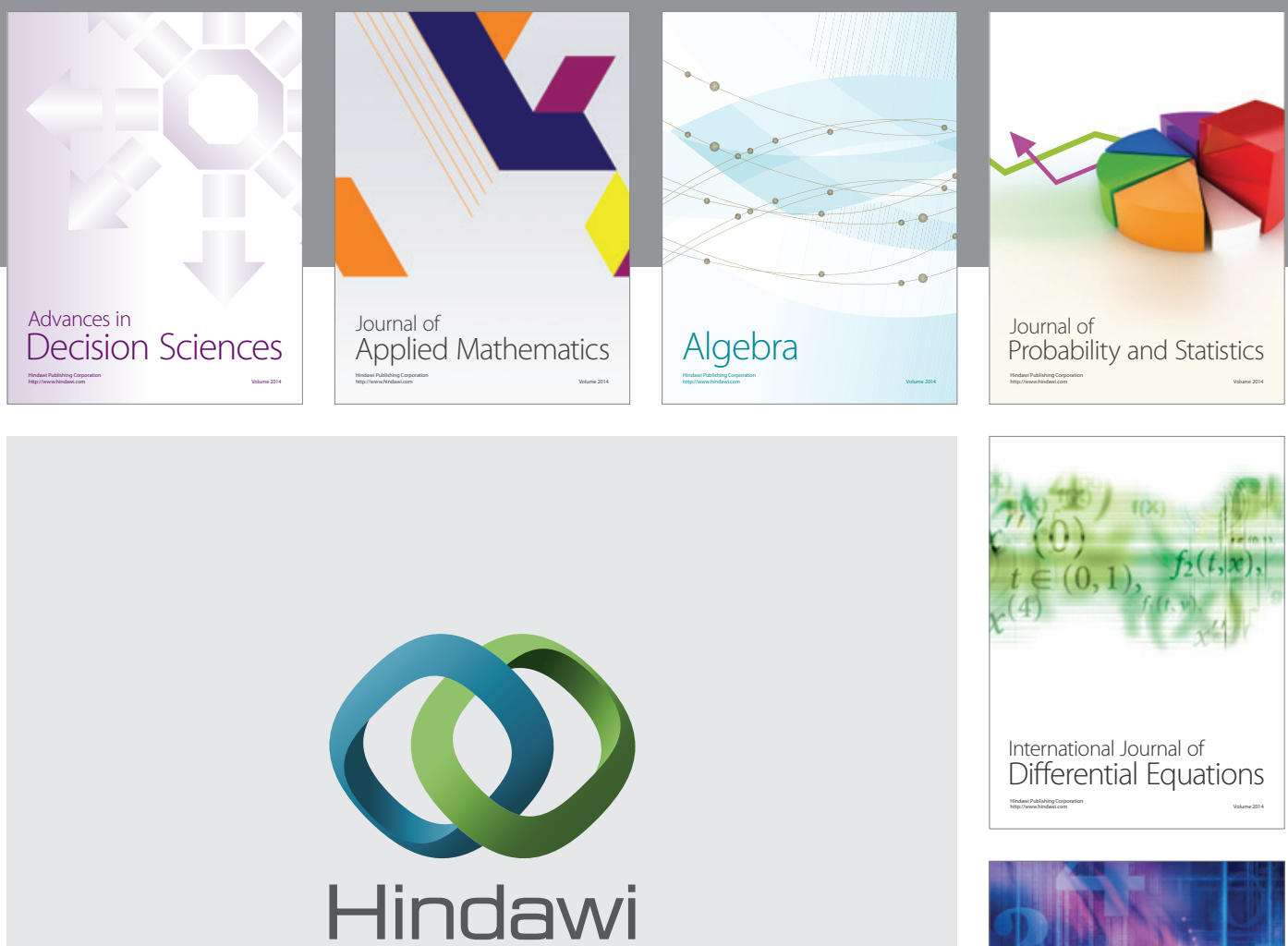

Submit your manuscripts at http://www.hindawi.com
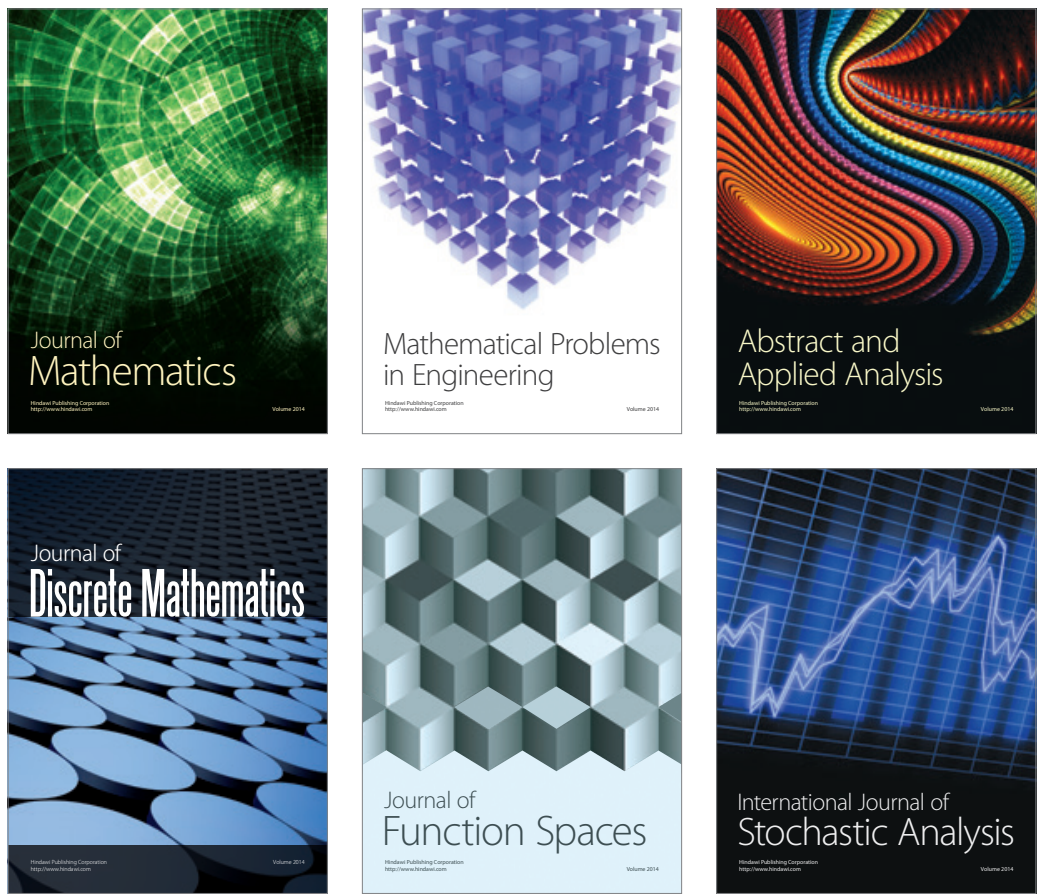

Journal of

Function Spaces

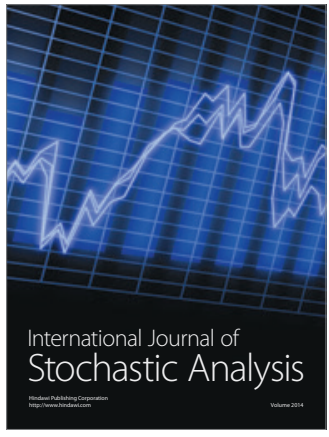

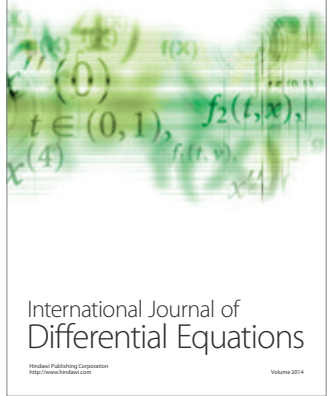
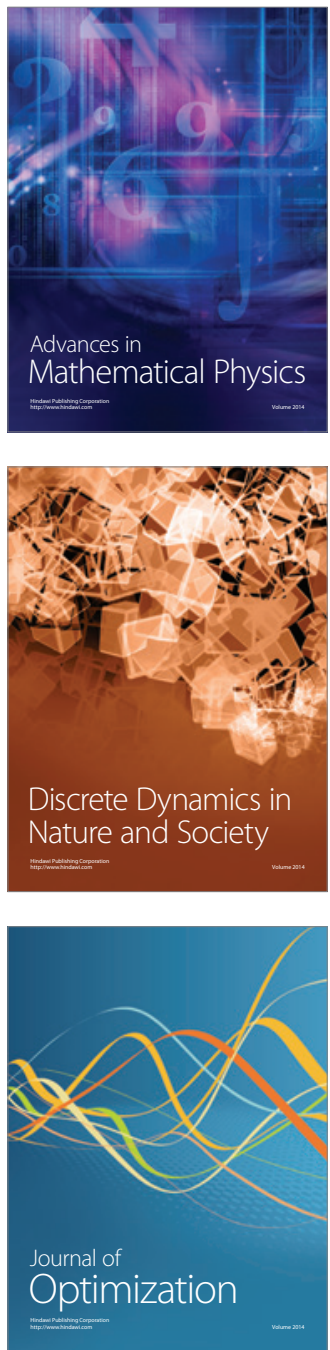